\title{
What Engages Doctoral Students in Biosciences in Doctoral Studies?
}

\author{
Viivi Virtanen ${ }^{1}$, Kirsi Pyhältö ${ }^{2}$ \\ ${ }^{1}$ Faculty of Bio- and Environmental Sciences, University of Helsinki, Helsinki, Finland \\ ${ }^{2}$ Centre for Research and Development in Higher Education, University of Helsinki, Helsinki, Finland \\ Email: viivi.virtanen@helsinki.fi
}

Received September $7^{\text {th }}, 2012$; revised October $3^{\text {rd }}, 2012$; accepted November $5^{\text {th }}, 2012$

\begin{abstract}
Reduced levels of engagement and dropping out have been identified as a major problem in doctoral education worldwide, including in the biosciences. Research suggests that engagement predict student satisfaction, degree completion, and persistence in studies. To explore the anatomy of engaging experiences altogether 40 doctoral students' theme interviews were analyzed by using abductive strategy. Accordingly, we were able to identify factors that promoted doctoral students' engagement in their work. In general, the students described many experiences of satisfaction, inspiration, joy, positive work drive, meaningfulness, and fulfillment in terms of their doctoral studies. The doctoral students' engagement in their work originated from various contexts of academic work, including research, scholarly communities, the supervisory relationship, and formal studies. The results indicate that although the interrelationship between individuals and the environment is complex and it is difficult to predict the outcome at an individual level, the central ingredients of engaging experiences among biosciences can be identified. Accordingly, activities that contribute to the doctoral students' sense of competence, autonomy, belonging, and contribution ought to be considered when trying to develop engaging learning environments for doctoral students. The results provide evidence-based tools for developing doctoral education in an academic environment.
\end{abstract}

Keywords: Doctoral Students; Positive Experiences; Engagement; Satisfaction

\section{Introduction}

Doctoral students form a highly skillful group based on their academic backgrounds. However, pursuing a $\mathrm{PhD}$ is a challenging journey. Previous research suggests that while some students find doctoral studies to be highly engaging there are number of doctoral students who never finish their thesis (Gardner, 2007; Nettles \& Millet, 2006). Attrition rates among doctoral students are suggested to range from $30 \%$ to up to $50 \%$, depending on the discipline and country (Bair \& Haworth, 2004; Golde, 2005; McAlpine \& Norton, 2006). Accordingly, reduced levels of engagement and dropping out have been identified as a major problem in doctoral education, including in biosciences (Pyhltö, Stubb, \& Tuomainen, 2011). Hence, there is a need to gain a better understanding about the anatomy of engaging doctoral experience to be able to develop more engaging learning environments for doctoral students. However, little is known about the factors and events that engage doctoral students in doctoral studies and contribute to resilience in facing challenges. The present study focuses on exploring episodes that promote doctoral student engagement in doctoral studies in the context of biosciences by studying the students' positive experiences. Thus, the study comes from a general framework of the positive psychology (e.g., Lopez \& Snyder, 2011; Marques, Pais-Ribeiro, \& Lopez, 2011; Myers, 2000; Rich, 2003).

\section{Theoretical Background}

Conducting doctoral research can be considered academic work. In carrying out doctoral research, doctoral students are taking their first steps as professional researchers in the academic field (Golde, 2005; Stubb, Pyhältö, \& Lonka, 2011). This is especially true in biosciences where doctoral studies are typically conducted in research groups.

\section{Work Engagement among Doctoral Students}

Work engagement refers to a positive, fulfilling, workrelated experience (Schaufeli, Martinez, Pinto, \& Bakker, 2002a) characterized by vigor, dedication, and absorption. It as characteristic of work engagement that engaged individuals feel energetic, effective, and focused on their work (Bakker, Schaufeli, Leiter, \& Taris, 2008). Absorption refers specifically to total concentration on and immersion in work characterized by the feeling of time passing quickly and difficulty detaching oneself from one's work (González-Romá, Schaufeli, Bakker, \& Lloret, 2006; Langelaan et al., 2006). Vigor refers to high levels of energy and mental resilience while working, the willingness to put considerable effort into the task, and persistence when facing difficulties (Schaufeli et al., 2002a). Thus, doctoral students who feel very vigorous when working on their doctoral project are highly motivated by the project and are also likely to show high persistence when encountering challenges and difficulties. A third dimension of work engagement, dedication, is characterized by a strong psychological involvement in one's work, combined with a sense of significance, enthusiasm, inspiration, pride, and challenge (Schaufeli et al., 2002a; CooperHakim \& Viswesvaran, 2005).

Accordingly, engaged individuals have been found to experience their work as satisfying and meaningful. This pro- 
motes work engagement and further protects individuals from negative states, such as exhaustion, that might lead to burnout (González-Romá et al., 2006; Hakanen, Bakker, \& Williams, 2006). Moreover, engaged persons are willing to invest their time and effort in their work, are efficient in dealing with the demands of their jobs, and have persistence even in the face of difficulties (Bakker et al., 2008; Schaufeli et al., 2002a; Schaufeli, Salanova, González-Romá, \& Bakker, 2002b). Hence, engaged doctoral students are likely to experience a high level of energy, to find their research work meaningful, and to remain very persistent when encountering problems during the doctoral journey than students who suffer from disengagement in their doctoral studies.

\section{The Working Environment Fit for Doctoral Students}

Research on work engagement has shown that various environmental as well as individual factors contribute to doctoral student engagement. For example, social support, constructive feedback, as well as a good supervisory relationship have been identified as predictors for doctoral students' satisfaction, studying persistence, and experienced well-being (Gardner, 2007, 2008; Golde, 2005; Ives \& Rowley, 2005; Pyhältö, Stubb, \& Lonka, 2009). The findings suggest that a doctoral students' engagement is regulated by the complex dynamic between the students and their working environment rather than a single personal or environmental attribute.

The dynamic interplay between doctoral students and their working environment can be explored in terms of personenvironment fit. Fit refers to the congruence between individuals and their environment (Edwards, 2008). Previous studies on work engagement suggest that perceived fit between the individuals and their working environment affects job satisfaction, turnover intensions, and well-being (Verquer, Beehr, \& Wagner, 2003). Further, research on doctoral experience indicates that the perceived fit or misfit between doctoral students and their working environment influences the students' doctoral experience and the completion of the process (Gardner, 2007). Golde (2005), for instance, found that a misfit between doctoral students' goals and expectations and the norms and practices of the scholarly community affected students' persistence.

However, the scholarly community is a complex and dynamic working environment that provides various arenas and forms of participation for doctoral students. This complexity is also reflected in doctoral students' experiences of their schoolarly communities. Pyhältö et al. (2009) found out that both the definitions of "scholarly community" given by the students and their experience of membership in this community varied considerably: about one third of $\mathrm{PhD}$ students felt isolated from their academic community or experienced the relation between themselves and the community as somehow problematic. Hence, sources of student engagement or the lack of it may vary, not only between scholarly communities but also between the working contexts provided by a single community. In terms of exploring the engagement of doctoral students, this suggests that different scholarly environment variables should not be summarized into a single measure.

Both the quantity and the quality of working environmentdoctoral student interaction are likely to contribute to experienced engagement (Bair \& Haworth, 2004; Pyhältö et al., 2011). Relationships between the student and the working environment that contribute to their sense of autonomy, competence, relatedness (SDT theory) (Deci \& Ryan, 1990, 2008) as well as a sense of contribution (Eccles, 2008) are suggested for promoting student engagement. This is partly in line with previous findings on doctoral experience indicating that a sense of belonging plays a central role in doctoral students' well-being and engagement in their studies (Austin, 2002; Pyhältö et al., 2009). Moreover, there is some evidence that an internal locus of control and self-direction is central to making the most of doctoral education (Anderson, 2011). Accordingly, it can be hypothesized that if doctoral student active agency (autonomy) in terms of their doctoral research, sense of belonging in the scholarly community (relatedness), perceived proficiency as a scholar (competence), as well as their sense of mattering (contribution) are facilitated, this may promote their engagement in their doctoral work. However, we do not really know much about what the central ingredients of an engaging doctoral experience are and what contributes to student engagement.

\section{This Study}

In the present study we focus on exploring the engaging experiences that may contribute to the development of the engagement of doctoral students in their thesis work in the various working contexts afforded by the scholarly community. More specifically, we focus on analyzing the episodes that affect and reshape the relationship between the doctoral students and their working environment and promote the students' engagement in their doctoral studies. The context of the investigation is biosciences. Our research hypothesis is that doctoral students' engaging experiences are embedded in various academic activities. By identifying the engaging experiences, scholarly communities can be facilitated in creating meaningful and engaging learning environments for their doctoral students.

Thus, the aim is to explore: What engaging experiences did the participants report? What factors contribute to student engagement in their doctoral project? How are the events and episodes situated in academic activities?

\section{Methods}

\section{Sample}

This study included interview data collected from doctoral students in biosciences at a major, research intensive university in Finland. Altogether 40 doctoral students were interviewed (male $=15$, female $=25)$. The participants were either just finished ( $\mathrm{n}=20$; mode 31 years) or were finishing their studies ( $\mathrm{n}$ $=20$; mode 26 years), and hence had the most recent experience of the doctoral path. All majors were represented by the participants, namely, Aquatic Sciences $(n=5)$, Biochemistry ( $=3)$, Ecology and Evolutionary Biology $(n=9)$, Environmental Sciences $(n=10)$, General Microbiology $(n=2)$, Genetics $(n=$ $4)$, Physiology $(n=4)$, and Plant Biology $(n=3)$. All the participants pursued their doctoral dissertation in English as a summary of articles, which includes four to five international refereed journal articles, an introduction, and a summary.

\section{Measurements and Data Collection}

The data was collected in 2009. The semi-structured theme interview included questions on the participants' reasons for entering doctoral training, their motivation and experiences, the practices of doctoral training and supervision, the problems and 
challenges encountered, their personal and collective resources, as well as ideas concerning how doctoral training should be organized. The interviews were tape-recorded digitally and transcribed into text files by a trained research assistant.

\section{The Procedure of the Interviews}

Firstly, the respondents were asked some background questions, such as their major and the topic of the thesis. Next, the respondents were asked to describe their $\mathrm{PhD}$ process, and to clarify, what are the key events or turning points that have had significant effect on the process, in their opinion. Then, the respondents were asked a number of questions to capture their positive experiences, such as: What do you find most rewarding about the doctoral thesis process? Please, describe one situation during your thesis process when you were inspired. What happened? Why? What were your reactions? What did you think and feel? Finally, the last question allowed the respondents to provide any other information they preferred to add, or to give any comments, e.g., about the interview.

\section{Analysis}

The data were analyzed using an abductive strategy. At the beginning of the analysis, a functional coding procedure was developed. The data analysis had features of the grounded theory approach, which emphasized the constant comparative method for assuring the accuracy of incident codes within each category and the purpose of generating theoretical properties for each category (Harry, Sturges, \& Klingner, 2005). At first, all the text segments in which doctoral students referred to engaging experiences, including positive emotions, satisfaction, work drive, and motivational boosts were coded into the same hermeneutic category. After this, the data were coded into four exclusive main categories: 1) a sense of competence including experiences of developing academic expertise; 2) a sense of contribution including experiences of producing significant scientific knowledge; 3) a sense of belonging, including experiences of being a member of a scholarly community; and 4) a sense of autonomy, including experiences of making one's own decisions, having an intrinsic motivation to study the topic, and being in control of one's own working life. The main categories reflected the sources of engagement reported by doctoral students. Finally, these four main categories were classified into five basic categories that constituted the primary context in which the engaging events were situated: 1) research activities, 2) the scholarly community, 3) the supervisory relationship, 4) doctoral course work, and 5) resources.

The categories resulting from the content analysis were validated by the research group at the end of each analysis phase (Miles \& Huberman, 1994). In the few cases of disagreement, consensus on the final categorization was reached in discussions between the researchers. The ecological validity of the findings was tested and verified in pedagogical training for supervisors in the university.

\section{Results}

\section{The Primary Sources of the Engaging Experiences}

The doctoral students reported a variety of engaging experiences $(f=314)$ ranging from short events to extensive series of episodes. The students described many experiences of satisfaction, inspiration, joy, positive work drive, meaningfulness, and fulfillment in terms of their doctoral studies. The engaging episodes were situated along the entire timeline of their doctoral journey. Further investigation showed that sources of the engaging experiences varied. The primary sources of the engaging experiences, described by the doctoral students were 1) a sense of belonging, 2) a sense of competence, 3) a sense of contribution, and 4) sense of autonomy.

Figure 1 shows that the participants often emphasized a sense of belonging as a primary source of studying engagement (36\%). They, for instance, described the importance of becoming and being a member of the scholarly community as a central resource in their work. Perceiving oneself as competent $(31 \%)$ as a junior researcher and developing one's expertise was regarded as satisfying by the participants. The participants also perceived a sense of contribution (17\%) as an ingredient in finding one's work meaningful, significant, and satisfying. Some participants' considered autonomy (16\%), including academic freedom and the possibility to be given responsibility and make their own choices in terms of their doctoral studies as an important asset in their work.

\section{A Sense of Belonging}

Characteristic of the situations in which the participants' sense of belonging was promoted was that interest, knowledge, expertise, practices, and challenges were shared with other researchers and that relatedness was experienced within the academic community. The participants also described various arenas of participation and collaborative learning, such as sharing research interests and receiving support with peers, and in supervisory relationships, research groups, and the international researcher community. One participant, for example, valued the interest that a senior researcher showed in that participant's doctoral project:

I met in a congress a women who had just the same, so, she puzzled over the same themes, the same problems, and the same questions... Then I wrote to her, and she was really kind and sent all her publications and much material to me, and almost without asking she sent all that to me. And then she also wished me good luck on my own research. It was such a first experience that then, I thought that people are really kind. So it really felt good then. (Student B6)

The students also regarded showing understanding and giving and receiving support and constructive feedback as central resources in conducting research. The participants, for example, reported the supervisor's contribution to their doctoral projects, such as helping to apply for grants, supporting international networking, giving constructive feedback on manuscripts, or

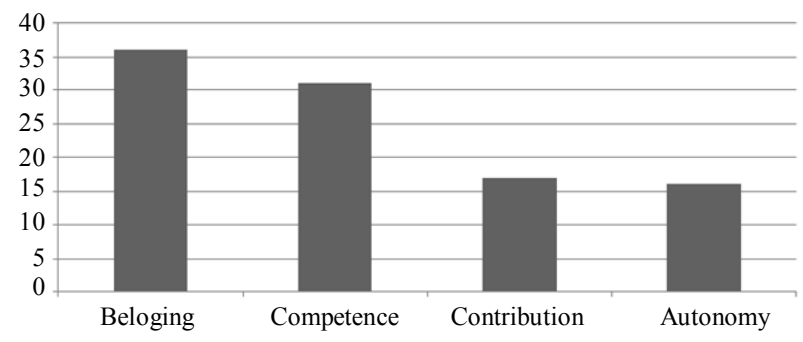

Figure 1.

The percentages $(\%)$ of the sources of the doctoral candidates' engageing experiences $(f=314)$. 
sharing the same research interests, to be often highly engaging. Also, the supervisor's ability to be pleasant, to encourage, or to show understanding were important to the students:

My supervisor dropped in once a week or so to help me with (experiments)..., and we really discussed how it is going and what the results are of that day..., so, there really was constant support and interaction. (Student A2)

Support and constructive feedback from members of the scholarly community were considered especially significant when facing problems, failures, and disappointments. However, sharing everyday experiences and work with peers and other members of the research group were considered source of engagement. The students, for example, described the importance of dialog with someone who understood their methods, objectives, and the whole research process, as the following excerpt shows:

We had a habit of wandering around with the printouts. Everyone always printed their own results and then wandered around with the printouts or took them to the coffee table saying, "Hey guys, look at this. Is there any sense in these?" The habit was really nice. (Student A20)

\section{A Sense of Competence}

The participants' sense of competence often emerged as their knowledge increased, or as they acquired other academic skills. Hence, in these events, engagement and satisfaction stemmed from the creation of new ideas and findings, learning, and development as a scholar. Accordingly, the students reported a variety of learning experiences that increased their efficacy as a researcher. They, for instance, described learning methods, new material, and coping strategies for dealing with the academic community. Many students especially seemed to enjoy the process of problem solving:

That it was really like shaking your own brains, so that one had to think from many perspectives, and then, when one realizes the relationship between things, it is really great. I think it is such an experience that one is unable to have if the process is predesigned. (Student A15)

Some students reflected on the whole of the doctoral experience in terms of learning. They often perceived doctoral studies as a personal development process in which they described acquiring academic scholarship step by step:

Then suddenly, you notice that making a presentation is not so difficult any longer, and you can use an old file to complete your new application for a grant. Also, that you in a way have knowledge. Then, you are not so sensitive anymore to reviewers' bad comments that you cry. You just curse, and start writing a response and defending your arguments. Thus, an allinclusive progress. (Student A5)

However, the students also described the development of more specific research skills and the satisfaction they gained from being good at the task at hand:

Of course, fieldwork has been in a way really enjoyable... fieldwork is something that I really can, I am able to do it, and afterwards it is a great feeling that one has come through something one knows that not so many could have been able to do. (Student B4)

Moreover, the participants described time periods, short events, "eureka moments", and specific episodes that contributed to their engagement. For example, satisfaction and joy caused by new discoveries were often reported. Getting good results were often perceived as one of the highlights of research. A student described the significance of the moments of actually receiving the results as one of the most important factors that kept that student engaged, although the everyday work was sometimes frustrating, as the following extract shows:

Well, there really goes a couple of weeks if you get really good results, you'll go bananas, and that keeps you going forward, but when you have done more research you learn that $90 \%$ of experiments fail, and that is just reality to live with, and you have to enjoy the successful moments ... (Student B11)

\section{A Sense of Contribution}

The experience of being a scientist and producing original scientific knowledge with significance was characteristic of the students' sense of contribution. Accordingly, a sense of contribution was highly embedded in conducting research. However, the focus of the contributions described by the students varied. Some of the students emphasized the contribution of their research to society, while others highlighted their contribution to the academic community. Being able to contribute to the academic community was considered especially rewarding by the students. Most often, the students described the possibility of contributing to academic research by producing new scientific knowledge that was often based on the students' own original idea, as the following extract shows:

In principle, the theme is really interesting in my opinion, and it is a good starting point. So one can get out of it such knowledge which has not been gotten so far, but it is quite challenging also. (Student B9)

Some students described dialogues between the members of academia from which collaborative learning emerged. The following extract shows an experience of contribution related to supervising:

My supervisor has the habit of getting excited about the topic, which gets me excited too, and then, when we both are in the mode of getting excited discussing the topic, it also feels that it is my thing. And not only the way that I contribute to the topic, but that I also have input in our discussion. (Student B19)

The scholarly community seemed to mean a great deal to doctoral students by offering opportunities to communicate about the topic. The interest that the experts, and sometimes peers, showed in the students' research theme seemed to promote doctoral students' experiences of contribution, if the student felt that his/her own input was meaningful to others as well. Also, the experiences where all the colleagues in one's own research group were putting effort towards the same goal, promoted engagement, as the following extract shows:

The most (rewarding) were the moments on a good team. Sometimes there emerged discussions where one felt that one was part of a bigger entity and research area. These (moments) were good and meaningful. And somehow there emerged: we do this together, and I am an important part of it. (Student A8)

\section{A Sense of Autonomy}

Further investigation showed that a sense of autonomy was also perceived as an ingredient in finding the doctoral journey engaging. A number of the students reported that they prefer to work as a researcher because that work is independent in nature or (and) the students expressed fascination with their research theme. The participants also reported that they liked having the 
academic freedom to organize their work on their own. These students mostly emphasized the independence to design the research process, including both contents and practices. Many students used the phrase "to have a free hand", meaning that they can decide how they use their time, as well as how they plan and do the research:

Well, the most rewarding has really been, which is good and bad, that I have had quite a free hand. I have been given space to lead myself, and there has been space for my own ideas and practices. I have never had difficulties in getting my voice heard, to do what I want to do. In that sense, it has really been rewarding that I have been allowed to do various things. I have seen (students) doing what many others have done before, using the same methods all the time. It is not as fun as when You can test and make mistakes. (Student B18)

Moreover, the opportunity to freely fulfill one's interests and ideas was perceived as a source of engagement. Some of the students described that they had applied for the project because the theme inspired them. They also seemed to be widely enthusiastic about their own research theme, which sometimes originated from their own ideas:

Mainly, one is actuated by one's own interest, which is rewarding. This does not feel like work. It is more like a hobby. I never feel like I am going to work. Every morning I feel really happy that I can come here, that one can choose such a profession. One does not have to choose a profession only to maximize income, but one can do what one really wants to." (Student B3).

\section{The Contexts of the Engaging Experiences}

The engaging episodes took place both in formal and informal events, ranging from presenting a paper at a congress to discussions during lunch breaks. The Figure 2 shows that the engaging experiences reported were often situated in research activities (40\%), the scholarly community $(35 \%)$, and within the supervisory relationship (22\%). Engaging episodes were less often situated in the formal course work $(3 \%)$ included in doctoral studies. Moreover, resources $(\geq 1 \%)$ were rarely emphasized in terms of experienced engagement in doctoral studies.

The participants described engaging experiences related to conducting research, for instance, making new discoveries and carrying out fieldwork. They also described their participation in various activities of scholarly communities, ranging from

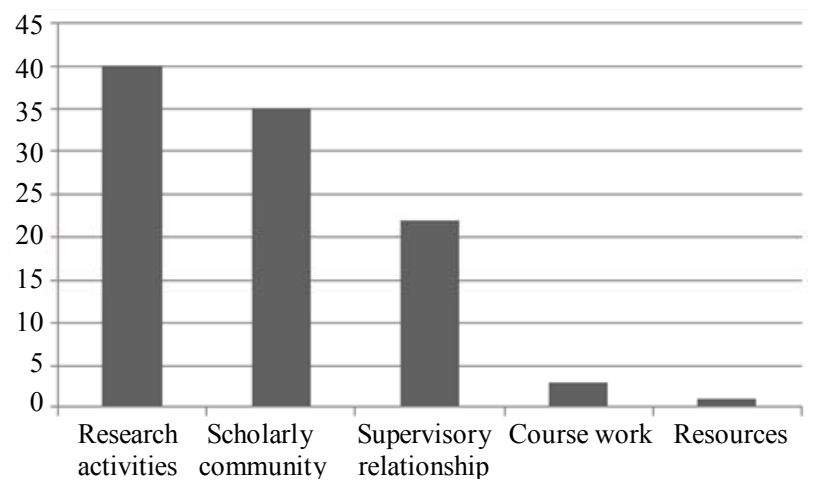

Figure 2.

The percentages of the engaging experiences $(f=314)$ situated in various activities of academic life. daily meetings and discussions with academics to giving conference papers. Also, the supervisory relationship, for example receiving constructive feedback, emotional support, and encouragement from the supervisor was reported to be important. Some of the students described engaging experiences situated in the formal course work included in doctoral studies. Only a few of the participants regarded financial resources and structures as significant in terms of their engagement. These students often reported to feel lucky that they did not have to worry about resources.

\section{Discussion}

To our knowledge, no previous studies have been conducted on the factors and episodes that contribute to the engagement of doctoral students in their thesis work in the context of biosciences. Hence, this study aimed at contributing to the advancement of the understanding of the basic ingredients of engaging doctoral experiences in this domain by exploring the episodes that contributed to the doctoral students' engagement in their thesis work. Our results showed that the doctoral students' satisfying and meaningful experiences in terms of their doctoral research were characterized by vigor, dedication, and absorption. Accordingly, work engagement literature seemed to provide a functional grounding for exploring doctoral students' engagement in their thesis work (Schaufeli et al., 2002a).

The study suggested that perceived autonomy, belonging, competence, and contribution were central ingredients in doctoral students' engagement in their doctoral work and that these ingredients may predict doctoral students' further satisfaction, studying persistence, and experienced well-being. A sense of belonging and competence in particular were emphasized as engaging experiences, whereas episodes promoting a sense of autonomy and contribution were less often reported. Doctoral students, for example, perceived supervisory support, constructive feedback as well as discussions with peers and senior researchers to be extremely important and inspiring. However, they also reported a variety of significant learning experiences that increased their expertise and efficacy as a researcher. Hence, both the context and content of the engaging experiences varied.

The findings are in line with self-determination theory (Deci \& Ryan, 2008), which suggests that students' intrinsic motivation, better achievement, and psychological well-being are facilitated when their senses of autonomy, competence, relatedness (Deci \& Ryan, 1990), and contribution (Eccles, 2008) are promoted. Moreover, the results indicate that, although the interrelationship between individuals and the environment is complex and it is difficult to predict outcomes at an individual level, the central ingredients of engaging doctoral experience among doctoral students in biosciences can be identified and hence promoted. Accordingly, we argue that such activities that contribute to the doctoral students' sense of competence, autonomy, belonging, and contribution ought to be considered in developing engaging learning environments for doctoral students.

Further investigation showed that the doctoral students' engagement in their work originated from various contexts of academic work, including research, scholarly communities, the supervisory relationship, and formal studies. Doctoral students, for instance, emphasized belonging to a scholarly community, a good supervisory relationship, meaningful courses, and re- 
search that mattered both personally and in terms of the schoolarly community as the key factors contributing to engagement in their studies. Moreover, variation was seen between the engaging episodes reported by the students in terms of the perceived significance, duration, and the point of the doctoral studies at which the episodes were situated. Conducting doctorral research, however, proved to be the primary context for the engaging experiences. The doctoral students, for instance, described absorption and even experiences of flow in research activities, including testing a hypothesis and making new discoveries that promoted their intrinsic motivation. However, the sources for student engagement varied between the working contexts provided by the scholarly community. The findings support previous research on doctoral experience (Gardner, 2007, 2008; Golde, 2005; Ives \& Rowley, 2005; Pyhältö et al., 2009; Stubb et al., 2011) suggesting that various environmental as well as individual factors contribute to doctoral students' experiences.

A high level of satisfaction is suggested to be an indicator of a good fit (Verquer et al., 2003) between the student and the academic working environment, which further contributes to learning outcomes and resilience when facing problems (Golde, 2005; Stubb et al., 2011). Accordingly, by studying the anatomy of doctoral students' engaging experiences, we are able to identify factors that predict student satisfaction, degree completion, and persistence in studies. Through these findings, we hope to provide evidence-based tools for the development of doctoral education. Future studies could investigate the relationship between doctoral students' engagement and their academic career development. We conclude that is worth focusing on if doctoral students' engagement predicts favorable outcomes, such as productivity.

\section{Methodological Reflections}

In this study, semi-structured interview data was collected to capture the narratives of episodes that promoted doctoral students' experiences of engagement. Hence, the aim was to explore the kinds of events that promoted student engagement. However, the individual doctoral students were not characterized in terms of their engagement experience, since the focus of this study was to explore events that contribute to student engagement rather than to identify students who are experiencing engagement. The reflective and process-oriented research design gave the doctoral students opportunity to reflect on various aspects of their work and thus the opportunity to study the perceived engagement. However, further research, especially with a longitudinal design, is needed to examine the development of engagement across an extended period of time.

The interview data was collected from 40 bioscience doctoral students from a large research intensive Finnish University. Because of the distinctive features of the discipline (McCune \& Hounsell, 2005; Lindblom-Ylänne, Trigwell, Nevgi, \& Ashwin, 2006) and the limited sample size, generalizing the results to other disciplines and in other countries should be done with caution. On the other hand, the semi-structured interviews provided rich data to identify and analyze the narratives of episodes that promoted doctoral student engagement in their thesis work. Accordingly, it allowed the exploration of engaging episodes embedded in a variety of practices of academia. Hence, these findings have transferability for further studies in the field of doctoral student engagement research.

\section{REFERENCES}

Anderson, B. (2011). Predictive relationships among learner characteristics, academic involvement, and doctoral education outcomes. Dissertation Doctor of Philosophy. Denton, TX: Department of Counseling and Higher Education, University of North Texas.

Austin, A. E. (2002). Preparing the next generation of faculty. Journal of Higher Education, 73, 94-122. doi:10.1353/jhe.2002.0001

Bair, C., \& Haworth, J. (2004). Doctoral student attrition and persistence: A meta-synthesis of research higher education. In J. C. Smart (Ed.), Higher Education: Handbook of Theory and Research 19 (pp. 481-534). Dordrecht: Kluwer Academic Publishers.

Bakker, A. B., Schaufeli, W. B., Leiter, M, P., \& Taris, T. W. (2008). Work engagement: An emerging concept in occupational health psychology. Work \& Stress, 22, 187-200. doi: $10.1080 / 02678370802393649$

Brown, S. P. (1996). A meta-analysis and review of organizational research on job involvement. Psychological Bulletin, 20, 235-255. doi: 10.1037/0033-2909.120.2.235

Cooper-Hakim, A., \& Viswesvaran, C. (2005). The construct of work commitment: Testing an integrative framework. Psychological Bulletin, 131, 241-259. doi:10.1037/0033-2909.131.2.241

Deci, E. L., \& Ryan, R. M. (1990). A motivational approach to self: Integration in personality. Nebraska Symposium on Motivation, 38, 237-288.

Deci, E. L., \& Ryan, R. M. (2008). Self-determination theory: A macrotheory of human motivation, development, and health. Canadian Psychological Association, 49, 182-185.

Eccles, J. S. (2008). Agency and structure in human development. Research in Human Development, 5, 231-243. doi: $10.1080 / 15427600802493973$

Edwards, J. R. (2008). Person-environment fit in organizations: An assessment of theoretical progress. The Academy of Management Annals, 2, 167-230. doi:10.1080/19416520802211503

Gardner, S. K. (2007). "I heard it through the grapevine" Doctoral student socialization in chemistry and history. Higher Education, 54, 723-740. doi:10.1007/s10734-006-9020-x

Gardner, S. K. (2008). Fitting the mold of graduate school: A qualitative study of socialization in doctoral education. Innovations in Higher Education, 33, 125-138. doi:10.1007/s10755-008-9068-x

Golde, C. M. (2005). The role of department and discipline in doctoral student attrition: Lessons from four departments. Journal of Higher Education, 76, 669-700. doi:10.1353/jhe.2005.0039

González-Romá, V., Schaufeli, W. B., Bakker, A. B., \& Lloret, S. (2006). Burnout and work engagement: Independent factors or opposite poles? Journal of Vocational Behavior, 68, 165-174. doi:10.1016/j.jvb.2005.01.003

Hakanen, J. J., Bakker, A. B., \& Williams, W. B. (2006). Burnout and work engagement among teachers. Journal of School Psychology, 43, 495-513. doi:10.1016/j.jsp.2005.11.001

Harry, B., Sturges, K. M., \& Klingner, J. K. (2005). Mapping the process: An exemplar of process and challenge in grounded theory analysis. Educational Researcher, 34, 3-13 doi: 10.3102/0013189X034002003

Ives, G., \& Rowley, G. (2005). Supervisor selection or allocation and continuity of supervision: Ph.D. students' progress and outcomes. Studies in Higher Education, 30, 535-555. doi: $10.1080 / 03075070500249161$

Kristof, A. L. (1996). Person-organization fit: An integrative review of its conceptualizations, measurements, and implications. Personnel Psychology, 49, 1-49. doi:10.1111/j.1744-6570.1996.tb01790.x

Langelaan, S., Bakker, A. B., Schaufeli, W. B., Van Rhenen, W., \& Van Doornen, L. J. P. (2006). Do burned-out and work-engaged employees differ in the functioning of the hypothalamic-pituitary-adrenal axis? Scandinavian Journal of Work, Environment, and Health, 32, 339-348. doi:10.5271/sjweh.1029

Lindblom-Ylänne, S., Trigwell, K., Nevgi, A., \& Ashwin, P. (2006). How approaches to teaching are affected by discipline and teaching context. Studies in Higher Education, 31, 285-298. doi: $10.1080 / 03075070600680539$

Llorens, S., Bakker, A. B., Schaufeli, W., McAlpine, L., \& Norton, J. 


\section{VIRTANEN, K. PYHÄLTÖ}

(2006). Reframing our approach to doctoral programs: An integrative framework for action and research. Higher Education Research \& Development, 25, 3-17. doi:10.1080/07294360500453012

Lopez, S. J., \& Snyder, (2009). The Oxford Handbook of Positive Psychology. New York: Oxford University Press.

McCune, V., \& Hounsell, D. (2005). The development of students' way of thinking and practicing in three final-year biology courses. Higher Education, 49, 255-289. doi:10.1007/s10734-004-6666-0

Marques, S., Pais-Ribeiro, J., \& Lopez, S. (2011). The role of positive psychology constructs in predicting mental health and academic achievement in children and adolescents: A two-year longitudinal study. Journal of Happiness Studies, 12, 1049-1062.

doi:10.1007/s10902-010-9244-4

Miles, M. B., \& Huberman, A. M. (1994). Qualitative data analysis: An expanded sourcebook. Thousand Oaks, CA: Sage.

Myers. D. G. (2000). The funds, friends, and faith of happy people. American Psychologist, 55, 56-67. doi:10.1037/0003-066X.55.1.56

Nettles, M. T., \& Millet, C. M. (2006). Three magic words: Getting to $P h D$. New York: The Johns Hopkins University Press.

Pyhältö, K., Stubb, J., \& Lonka K. (2009). Developing scholarly communities as learning environments for doctoral students. International Journal for Academic Development, 14, 221-232. doi:10.1080/13601440903106551

Pyhältö, K., Stubb, J., \& Tuomainen, J. (2011). International evaluation of research and Doctoral Education at the University of Helsinki-
To the top and out to society. Summary report on Doctoral students' and principal investigators' Doctoral training experiences. URL (last checked 28 September 2012).

http://wiki.helsinki.fi/display/evaluation2011/Survey+on+doctoral+tr aining

Rich, G. J. (2003). The positive psychology of youth and adolescence. Journal of Youth and Adolescence, 32, 1-3. doi:10.1023/A:1021017421413

Schaufeli, W. B., Martínez, I. M., Pinto, A. M., Salanova, M., \& Bakker, A. B. (2002a). Burnout and engagement in university students a cross-national study. Journal of Cross-Cultural Psychology, 33, $464-$ 481 doi:10.1177/0022022102033005003

Schaufeli, W. B., Salanova, M., González-Romá, V., \& Bakker, A. B. (2002b). The measurement of engagement and burnout: A two sample confirmatory factor analytic approach. Journal of Happiness Studies, 3, 71-92. doi:10.1023/A:1015630930326

Stubb, J., Pyhältö, K., \& Lonka, K. (2011). Balancing between inspiration and exhaustion? Ph.D. students' experienced socio-psychological well-being. Studies in Continuing Education, 33, 33-50. doi:10.1080/0158037X.2010.515572

Verquer, M. L., \& Beehr, T.A., Wagner, S. H. A. (2003). A metaanalysis of relations between person-organization fit and work attitudes. Journal of Vocational Behavior, 63, 473-489.

doi:10.1016/S0001-8791(02)00036-2 